\title{
Research on Model and Simulation of Hydraulic Lifting System of the Wave Power Generating Platform based on AMESim
}

\author{
Weinan $\mathrm{CaO}^{1, \mathrm{a}}$, Detang $\mathrm{Li}^{1,3, \mathrm{~b}}$, Zhengshou $\mathrm{Chen}^{3}$, \\ Wentao Tang ${ }^{1, c}$, Qin Lv ${ }^{1, d}$,Man Huang ${ }^{2, e}$ \\ ${ }^{1}$ Ship and Marine Engineering College of Zhejiang Ocean University, Zhoushan, 316022,China \\ ${ }^{2}$ Shipping and Port Construction Engineering College of Zhejiang Ocean University, Zhoushan, \\ 316022, China \\ ${ }^{3}$ Zhejiang Ouhua Shipbuilding Co.,Ltd,Zhejiang, Zhoushan,316101

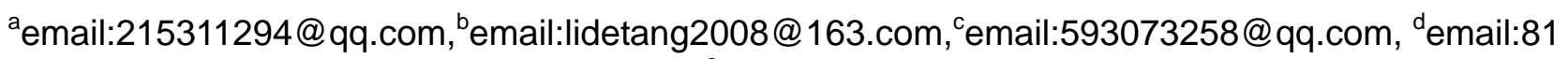

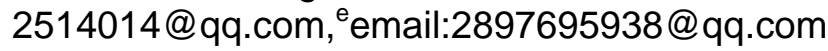
Keywords: Wave power generation platform, Lifting system, AMESim software, Model and
simulation

\begin{abstract}
The paper will analyze the necessity of research on Model and Simulation of ocean wave power generation platform of hydraulic lifting system. Aiming to the working condition and mechanism of self-elevating power-generating platform ,the paper will provide overall designing scheme and analyze the working principle of the system .By modeling and simulation of hydraulic system based on AMESim to set diffient parameter values for analysis of dynamic characteristics and stability of the system, which can help to find out the factors that influence the dynamic characteristics.This founding has a certain significant guiding meaning for the parameter optimization design of the jack up platform of hydraulic lifting system.
\end{abstract}

\section{Introduction}

With the constant development of world development, the global sources have suffered excessive exploitation and utilization which have made the available energy on the land depleted gradually[1]. The lack of the energy controls the economical development of each country directly. While the vast ocean reserves a huge capacity of various energy, one of which named wave power is an inexhaustible and renewable energy. Moreover using wave energy to generate power is one of the important means of gaining energy from the ocean. This paper, based on the national Marine renewable energy special fund project, regarding the self-protective device which can generate the power efficiently and stably by wave energy even though under severe ocean condition, aims to the study of power generation platform lifting system.

\section{The Composition and Working Principle of Lifting System}

Lifting Platform system, which is installed in the junction of the legs and the main platform in general, through the hydraulic lifting gear to drive main body of the platform to up and down .Platform is supported by three pile legs, and each leg has four main oil cylinder. One is connected to the main oil cylinder of ring beam and one is fixed on the main cylinder and the ring beam of platform's main body.Among them, the high ring beam has four bolts and the lower ring beam has four.

On the process of ascension:pull up bolt, rise the piston of main oil cylinder for a pitch, insert the latch after alignment pin hole, and then pull out the lower bolt, the main oil cylinder piston withdraw , finally to rise platform a pitch, after inserting the lower bolt, an ascending work cycle of platform is completed[2]. Then pull out the bolt, the oil cylinder piston extends a pitch, circulation system will enter into the next operating cycle. Through such repeated cycle process, platform will eventually be up to the job position. The working principle of the platform to fall down, put in and take out the plug is same as the process when it raises. 


\section{The composition of hydraulic system}

Lifting system of wave -power -platform is mainly composed of hydraulic cylinder, balancing valves, solenoid directional control valve, relief valve and the variable pump, the principle of the system is shown in figure 1 :

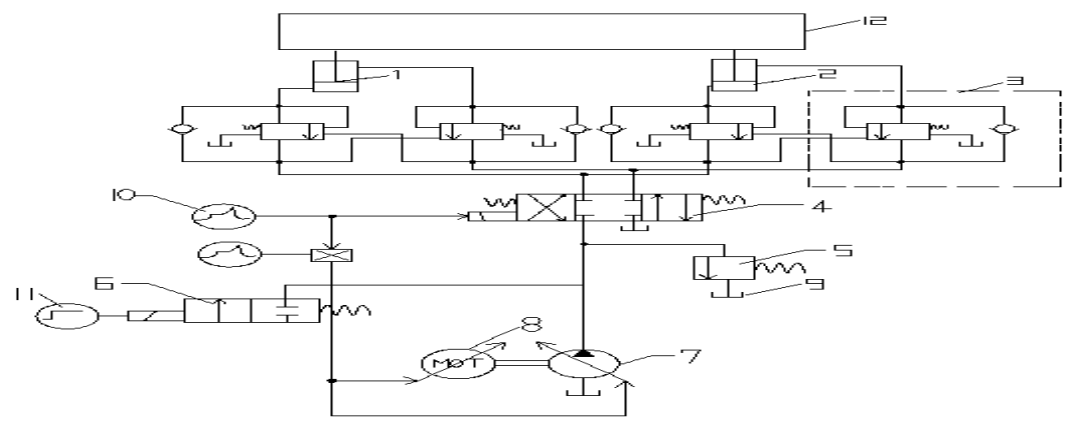

1. Hydraulic cylinder 12 . Hydraulic cylinder 2 3. The balance valve 4 . Three four-way electromagnetic directional valve 5 . Overflow valve 6 . Two two-way valve 7 . Variable pump

8.Motor 9.fuel tank 10.11. Source 12. Platform main body

FIG.1. The principle diagram of the hydraulic lifting system

\section{Modeling and Simulation on Lifting System}

1. model of the system

Modeling and stimulation, using the machine shop, hydraulic libraries and signal control in the AMESim software, which mainly includes four patterns: Sketch mode, sub models, Parameter mode and Simulation model[3]. AMESim sketch mode,according to the working principle of lift platform system model, as shown in figure 2:

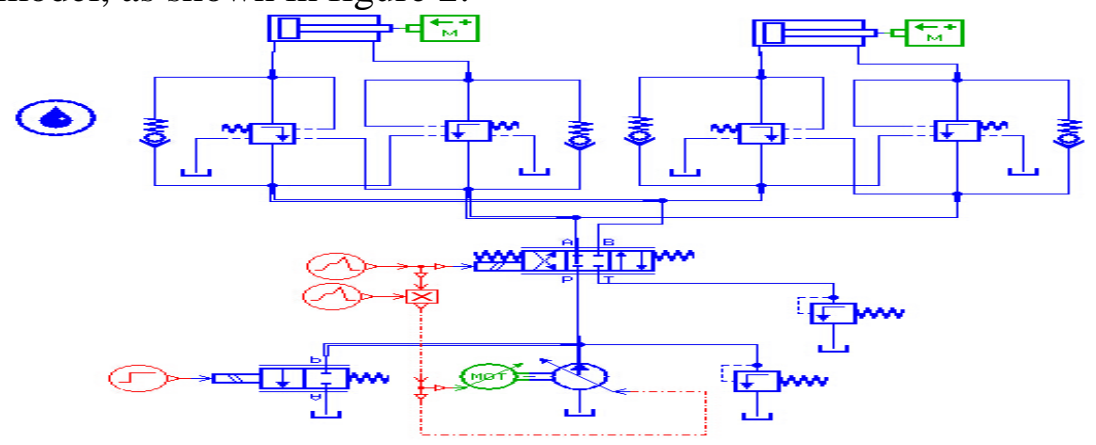

FIG.2. Hydraulic elevator system simulation diagram

2. set up the simulation parameters

Parameter settings in the AMESim modeling plays a very important role, parameter selection is reasonable directly related to the results of the simulation accuracy. Into the (Parameter mode) into the Parameter model, the element parameters of the system Settings

element Parameter Settings

\begin{tabular}{ll}
\hline Motor & $1400 \mathrm{rev} / \mathrm{min}$ for 0 to $15 \mathrm{~s}$ and 30 to $45 \mathrm{~s}, 900 \mathrm{rev} / \mathrm{min}$ \\
Variable pump & for 15 to $30 \mathrm{~s}$ and 45 to $60 \mathrm{~s}$ \\
& $1400 \mathrm{rev} / \mathrm{min}$ for 0 to 15 and 30 to $45 \mathrm{~s}, 900 \mathrm{rev} / \mathrm{min}$ \\
& for 15 to $30 \mathrm{~s}$ and 45 to $60 \mathrm{~s}$, displacement is $100 \mathrm{cc} / \mathrm{rev}$
\end{tabular}

Signal source

1400null for 0 to 15 s and 30 to 45 s,900null for 15

to $30 \mathrm{~s}$ and 45 to $60 \mathrm{~s}$ 
Three four-way valve

Balancing valve

The hydraulic cylinder

Hydraulic cylinder stroke

Unloading overflow valve

Safety relief valve maximum opening flow is $140 \mathrm{~L} / \mathrm{min}$ pressure dropis1bar,Damping ratio is 8null opening pressure is300bar

the piston diameter is $300 \mathrm{~mm}$ The piston rod diameter is $180 \mathrm{~mm}$

$80 \mathrm{~mm}$

opening pressure is 300bar

opening pressure is $100 \mathrm{ba}$

In the process of system simulation, ignoring the pipeline's impact on the oil pressure[4]. Set up the simulation time about $60 \mathrm{~s}$,sampling interval is $0.01 \mathrm{~s}$, and then start the simulation.

\section{The results of simulation analysis}

1.The realization of the function

Platform of ascending and descending movements' smooth conversion is the key to the design, it should try to reduce the speed fluctuation in the process of transformation to realize smooth transition[3]. In continuous work, the working conditions of all the working periods should be consistent to complete equal expansion amount of the same displacement oil cylinder. In the hydraulic cylinder 1 , for example, velocity and displacement curve are shown in figure 3, 4, 5:

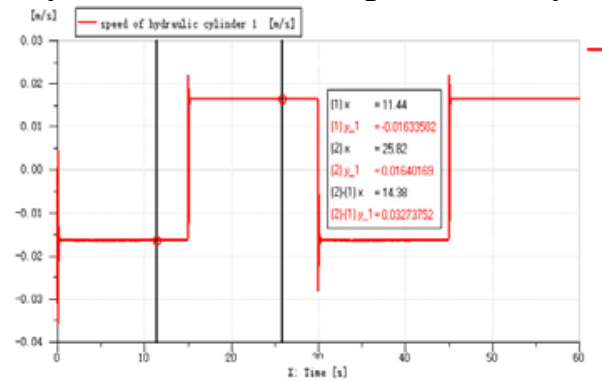

FIG.3. The first cycle speed

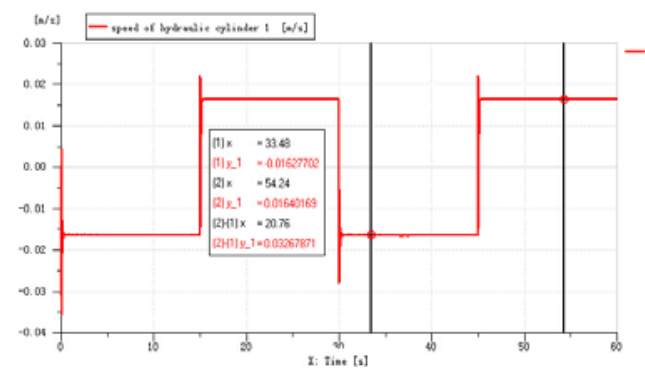

FIG.4. The second cycle speed

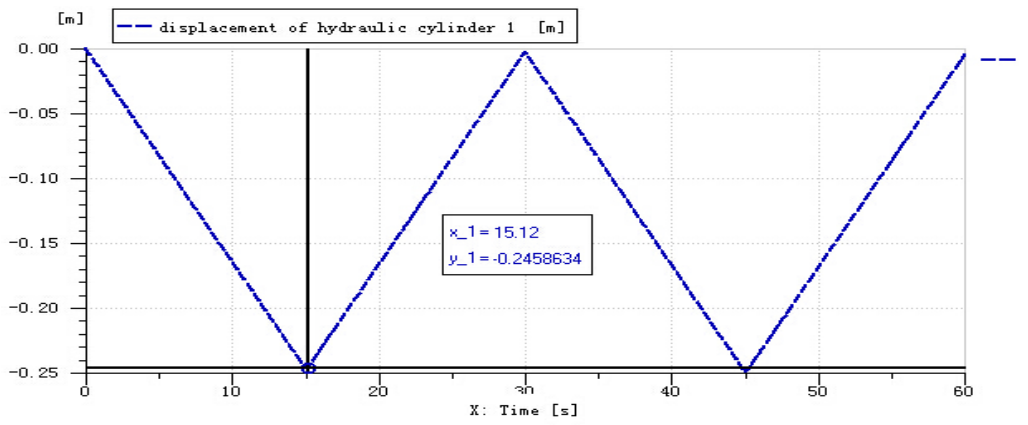

FIG.5. Cylinder displacement curve

From figure 3, the 30 seconds of the first cycle, in the process of the oil cylinder action from rise to fall appears small amplitude fluctuation which can be understood as to achieve the smooth transition. Rising velocity (1) = y - 1-0.01643748 m/s, decreasing speed (2) y - $1=0.01640169 \mathrm{~m} / \mathrm{s}$, error is negligible, and can be understood as a equal speed.

From figure 4, $30-60 \mathrm{~s}$ within the second cycle, (1) = y - 1-0.01630064 m/s, (2) y $-2=$ 0.01640169 , in the range of allowable error, two speed equals the speed during the first cycle, respectively.

In figure 5, oil cylinder for 0-15,30 to $45 \mathrm{~s}$ are in rise stage; For 15 - 30 and 45 - 60 s cylinder are in decline phase. Oil cylinder maximum displacement is y $-1=0.246 \mathrm{~m}$, cylinder can reach it's farthest location, will also be able to return to it's starting point, ensure the smooth implementation of the action. In the figure all paragraphs' displacement curve approximate to a straight line, thus proves the speed stability, smooth implementation of platform. 
2.the analysis of system stability

Set each parameter of the components of the system, observe the dynamic response of the system, and analyze the stability of the system[5]. The input signal is set to $60 \mathrm{~s}, 0-15,30-45 \mathrm{~s}$ for positive, three four-way valve on the left at this time, the hydraulic cylinder stretched out; Negative for 15 - 30 and 45 - $60 \mathrm{~s}$, three four-way valve in the right place at this time, the hydraulic cylinder draws back. According to the results of simulation, two hydraulic cylinder speed curves respectively are shown in figure 6, 7:

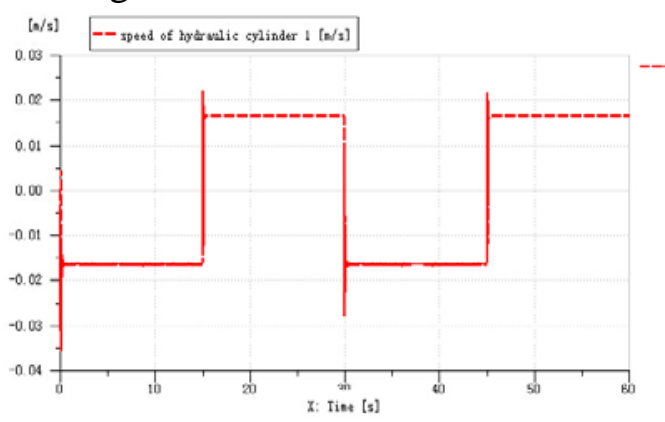

FIG.6. Velocity curve of cylinder 1

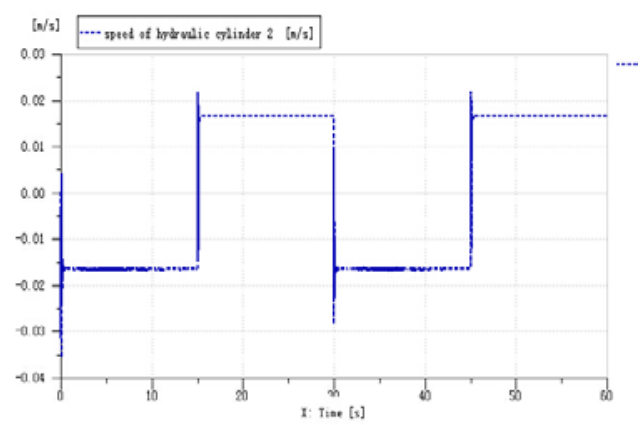

FIG.7. Velocity curve of cylinder 2

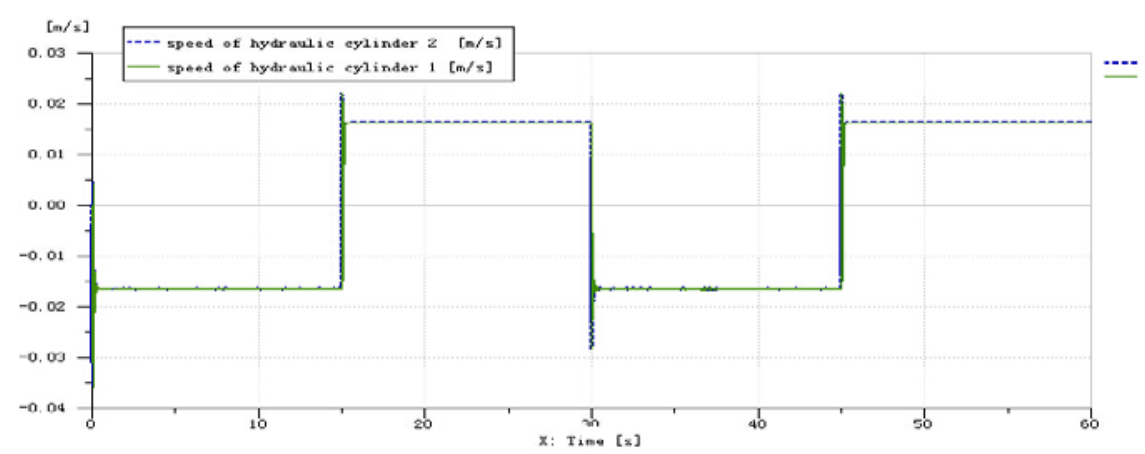

FIG.8. Comparison of two hydraulic cylinder speed curve

The figure 8 shows that in a short time at the beginning, the speed of the hydraulic cylinder is of volatility, then gradually stabilized and achieve dynamic balance state, two hydraulic cylinder speed curve almost overlap, and hydraulic cylinder moves smoothly. In the reversing process of hydraulic cylinder, for the pressure changes suddenly, at this time the speed of the hydraulic cylinder in a short period of time appears larger fluctuation, then gradually stabilized. The simulation results accord with the practical operation of the hydraulic cylinder. Known from the analysis of the above, the reasonable selection of various parameters of the system, the stability of the system is higher, smooth operation, can satisfy the requirements of the lifting platform running smoothly[5].

\section{Validation formula}

The results of simulation verification, verify the correctness of the hydraulic cylinder speed. Oil cylinder piston movement speed:

$$
v=S / T(\mathrm{~m} / \mathrm{s})
$$

In formul: $\mathrm{S}$ for piston stroke (m), $\mathrm{T}$ for the total travel time of the piston in a single direction (S).

Below figure 9 are the displacement curve for mass 1 , when $\mathrm{X}-1=15 \mathrm{~s}, \mathrm{Y}-1=-0.2463005 \mathrm{~m}$ gets maximum displacement. 


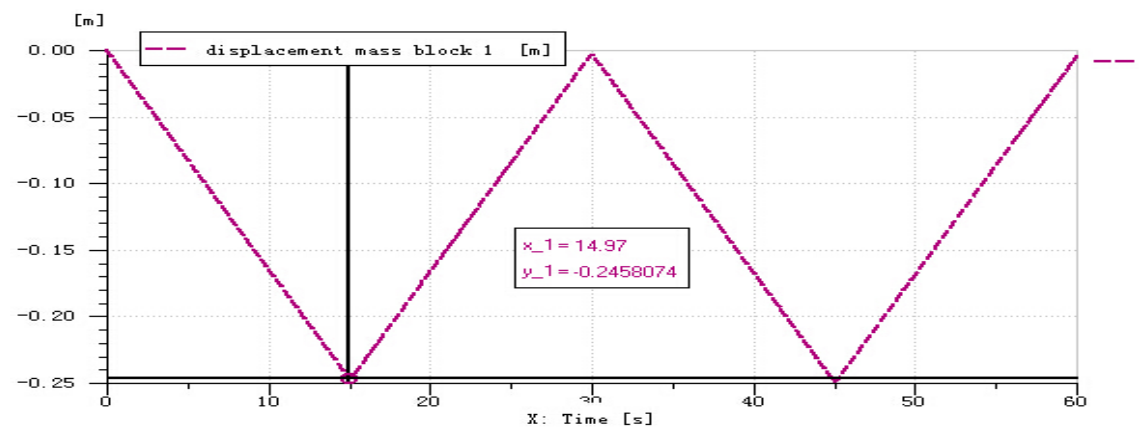

FIG.9. Displacement curve of mass 1

Put $\mathrm{S}=0.2463005 \mathrm{~m}, \mathrm{~T}=15 \mathrm{~s}$ into the formula (1), get the piston movement speed = $0.016420333 \mathrm{~m} / \mathrm{S}$, in the range of allowable error, the speed of the first cycle in figure 3 and second cycle in figure four are basic in agreement, validate the correctness of the simulation results.

\section{Conclusion}

In this paper,we can draw the following conclusion:

(1)Using AMESim software can effectively simulate the ocean wave power hydraulic lifting system, the rationality and correctness of each circuit and the whole design of the system are proved.

(2)Under the condition that each Component parameter is set reasonably, the output displacement and velocity of the hydraulic cylinder will be in a state of dynamic balance, and the system will run smoothly as well.

\section{Acknowledgements}

The author would like to thank the National Natural Science Foundation of China and The National Ocean Bureau of China special funds for renewable energy project under Contract no.ZJME2011BL04. This work was also supported by the Research Foundation of the State Key Ocean Engineering Laboratory of Shanghai Jiao Tong University under Contract no.1205 and the Zhejiang Provincial Natural Science Foundation of China under Contract no.Y5100180.

\section{References}

[1] Y.Sun, “Offshore platform hydraulic lifting system simulation research,”Marine Engineering, no.1,vol.26,pp.93-94,2008.

[2]Y.Fu\&X.Qi, “The Manual of System Modeling \& Simulation Reference for LMS Imagine.LabAMESim,"Beijing university of aeronautics and astronautics press, Beijing, vol.1,2011.

[3] H.Tian\&D.Li, “The hydraulic lift system design of Victory of oil production platform ,"Oil Field Equipment, no. 3,vol.33,pp.80-82,2004.

[4] W.Yang,B.Yan\&Z.Wang, “the analysis of system parameters optimization for heading machine based on AMESim,”Machine Tool \& Hydraulics, Machine Tool \& Hydraulics.

[5]Wilfrid Marquis -Favre,Eric Bideaux,Serge Scavarda.A planarmechanical library in the AMESim simulation soft-ware.Part I:Formulation of dynamics equations.Simula-tion Modeling Practice and Theory, 2005.3.17. 